\title{
Oxidative remote induction of type 3 deiodinase impacts nonthyroidal illness syndrome
}

\author{
Tatiana Ederich Lehnen*, Rafael Marschner*, Fernanda Dias, Ana Luiza Maia and Simone Magagnin Wajner \\ Thyroid Section, Endocrine Division, Hospital de Clínicas de Porto Alegre, Universidade Federal do Rio Grande do Sul, Porto Alegre, RS, Brasil \\ Correspondence should be addressed to S M Wajner: simonewajner@gmail.com
}

*(T E Lehnen and R Marschner contributed equally to this work)

\begin{abstract}
Imbalances in redox status modulate type 3 deiodinase induction in nonthyroidal illness syndrome. However, the underlying mechanisms that lead to D3 dysfunction under redox imbalance are still poorly understood. Here we evaluated D3 induction, redox homeostasis, and their interrelationships in the liver, muscle, and brain in an animal model of NTIS. Male Wistar rats were subjected to left anterior coronary artery occlusion and randomly separated into two groups and treated or not (placebo) with the antioxidant $\mathrm{N}$-acetylcysteine. Sham animals were used as controls. Animals were killed 10 or 28 days post-MI induction and tissues were immediately frozen for biochemical analysis. D3 activity, protein oxidation and antioxidant defenses were measured in liver, muscle, and brain. Compared to those of the sham group, the levels of D3 expression and activity were increased in the liver $(P=0.002)$, muscle $(P=0.03)$ and brain $(P=0.01)$ in the placebo group. All tissues from the placebo animals showed increased carbonyl groups $(P<0.001)$ and diminished sulfhydryl levels $(P<0.001)$. Glutathione levels were decreased and glutathione disulfide levels were augmented in all examined tissues. The liver and muscle showed augmented levels of glutathione peroxidase, glutathione reductase and thioredoxin reductase activity $(P=0.001)$. NAC prevented all the alterations described previously. D3 dysfunction in all tissues correlates with post-MIinduced protein oxidative damage and altered antioxidant defenses. NAC treatment prevents D3 dysfunction, indicating that reversible redox-related remote D3 activation explains, at least in part, the thyroid hormone derangements of NTIS.
\end{abstract}

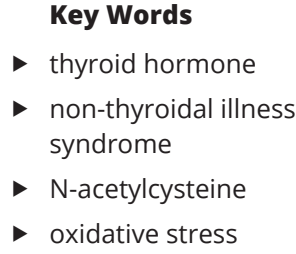

Journal of Endocrinology (2020) 246, 237-246

\section{Introduction}

Nonthyroidal illness syndrome (NTIS), also known as low T3 syndrome, is a clinical condition observed in ill patients characterized by a rapid decrease in serum triiodothyronine (T3) levels accompanied by increased reverse $\mathrm{T} 3$ (rT3) and a subsequent decrease in plasma thyroxine (T4), without alteration in thyroid stimulating hormone (TSH) levels (Wajner \& Maia 2012). NTIS is observed in patients with several diseases, and low serum T3 levels are inversely correlated with mortality in this condition (Iervasi et al. 2003, Peeters et al. 2005, Alevizaki et al. 2007). The pathophysiology of NTIS includes profound changes in peripheral thyroid hormone metabolism. This process is carried by a set of enzymes, deiodinase type 1, 2 and 3 (D1, D2 and D3, respectively). D1 and D2 convert $\mathrm{T} 4$ to $\mathrm{T} 3$, while $\mathrm{D} 3$ exclusively inactivates both $\mathrm{T} 4$ and T3. Deiodinases are 
oxidoreductases that benefit from reduced environment to achieve full activity (Kuiper et al. 2002). All three deiodinases require a cofactor that has yet to be identified, probably a thiol, which acts as a reducing agent releasing iodine from the selenocysteine residue thus regenerating the active enzyme.

Although the mechanisms leading to NTIS are not completely understood, changes in the redox state are known to alter deiodinase function (Wajner et al. 2011). The underlying pathways involved in this process are still a matter of study, but the deiodinase function depends on being in an oxidative or reductive state (Kuiper et al. 2002, Lu \& Holmgren 2009). The results obtained thus far suggest that D3 induction is correlated with augmented cellular stress and that the restoration of its activity seems to depend on the normalization of intracellular antioxidant levels, mostly that of glutathione (GSH). In this context, it has been recently demonstrated that antioxidants such as thioredoxins and glutaredoxins reduce the oxidized D3 state. Moreover, D3 has a close structural similarity with peroxiredoxin, with the transitory oxidized D3 enzyme able to recycle to its reduced form (Schweizer et al. 2014). Cysteine residues in the protein can be reversibly modified by oxidation to form intermolecular and intramolecular disulfide bonds and/or GSH-mixed disulfides (Bechtel \& Weerapana 2017). On the other hand, N-acetylcysteine (NAC, a major cysteine donator) increases intracellular cysteine and GSH levels and is capable of correcting the deiodinases function and thus the metabolism of thyroid hormones (Wajner et al. 2011, 2015). The glutathione-related enzymes glutathione peroxidase - GPx and glutathione reductase - GR, regulate GSH levels and are involved in detoxification and tissue antioxidant protection, which are critical in a disease state.

Among the mechanisms that lead to decreased T3 levels in NTIS is the action of oxidative stress on deiodinase function, which is induced through several pathways, most of which remain unknown. Redox homeostasis is a regulator of D3 function and augmented oxidative protein levels are observed in serum. Therefore, the role of these alterations is an open question: can they affect D3 systemically during disease, regardless of the primary targeted organ, to contribute to the decrease in T3 levels that is observed in illness? Thus, in this study, we aimed to evaluate D3 expression and activity in the liver, skeletal muscle and brain in an animal model of NTIS. We also evaluated the interrelationship between D3 induction and redox homeostasis.

\section{Materials and methods}

\section{Reagents}

Reagents were obtained from Invitrogen (Life Technologies), Calbiochem-Novabiochem or SigmaAldrich.

\section{Animals and procedures}

Male Wistar rats (weighing $\pm 250 \mathrm{~g}$ ) were used in the experiments. All procedures and experiments involving animals followed the recommendations of the Brazilian College of Animal Experimentation (COBEA). Our study was per the ethical principles of the Guide for the Care and Use of Laboratory Animals (NIH 1996) and the international standards for animal research of the Guidelines for Reporting Animal Research (Kilkenny et al . 2010). The Research Ethics Committee of our institution and the Animal Ethics Committee of the Hospital de Clínicas de Porto Alegre (CEUA-HCPP approved this study (Protocol \#130501)). All animals received standard food and water ad libitum and were kept in an air-conditioned room in cages under 12 hour light:12 h darkness cycles.

Briefly, MI was induced by anterior descending artery ligation, as previously described (Pfeffer et al. 1979), resulting in infarction of the left ventricle (LV) free wall. Twelve hours after surgery, echocardiography was performed to measure cardiac parameters and to determine the MI extension. Blood was collected for troponin measurements to confirm successful MI induction. The animals were divided into three groups (10 or 28 days of follow-up): Sham group ( $n=10$, 5 animals in each group at 10 and 28 days); MI-placebo group (infarcted animals that received intraperitoneal (IP) saline solution, every $12 \mathrm{~h}$ for $48 \mathrm{~h},(n=10$ animals at 10 and 28 days), and MI-NAC group, infarcted animals that received IP NAC $(10 \mathrm{mg} / \mathrm{kg}$, every $12 \mathrm{~h}$ for $48 \mathrm{~h}(n=10$ animals at 10 and 28 days). Previous publications showed that while the damage caused by MI is still evolving at 10 days, neither T3 levels nor echocardiographic parameters changed at 28 days post-MI (Olivares et al. 2007, Pol et al. 2011). Serial measurements of serum TSH, T4, T3, and rT3 levels were performed on the day of the procedure and at 10 or 28 days after surgery to confirm NTIS (Lehnen et al. 2017). Briefly, compared to baseline, serum T3 levels were decreased in MI-placebo animals at 10 (108 to $88.4 \mathrm{ng} / \mathrm{dL}, P<0.01)$ and 28 days $(108.5$ to $91.6 \mathrm{ng} / \mathrm{dL}$, $P<0.03)$, whereas no significant decreases in T3 levels were observed in MI-NAC animals at 10 or 28 days (Lehnen et al. 2017). At the end of each experimental period https://joe.bioscientifica.com https://doi.org/10.1530/JOE-19-0574 (c) 2020 Society for Endocrinology Published by Bioscientifica Ltd. Printed in Great Britain 
(10 or 28 days), the animals were killed (anesthetized with the vaporizer (Surgivet, Saint Louis, MN, USA)) and liver, gastrocnemius muscle, and brain were removed, snap frozen in liquid nitrogen, and stored at $-80^{\circ} \mathrm{C}$. The experiments presented in this manuscript were performed using the collected tissues.

\section{D3 activity assay}

D3 activity in tissue samples was determined using paper chromatography, as previously described (Huang et al. 2005). Briefly, tissues were homogenized and sonicated with $10 \mathrm{mM}$ Tris- $\mathrm{HCl}, 0.25$ sucrose buffer $(\mathrm{pH} 7.5)$, and $10 \mathrm{mM}$ dithiothreitol (DTT). Protein concentration quantified by Bradford assay. The homogenates were incubated for an hour with 200,000 cpm 125I-labeled T3, $2 \mathrm{nM} \mathrm{T3}, 20 \mathrm{mM}$ DTT, and $1 \mathrm{mM}$ propylthiouracil (PTU) to inhibit any D1 activity. The addition of $200 \mathrm{nM}$ of T3 completely abolished D3 activity in all samples. The reaction was stopped with $200 \mu \mathrm{L}$ ethanol $95 \%, 50 \mu \mathrm{L} \mathrm{NaOH}$ $(0.04 \mathrm{~N})$, and $5 \mathrm{mg}$ PTU. Deiodination was determined based on the amount of 125I-3, 3'-T2 generated. Results were expressed as the fraction of $\mathrm{T} 2$ counts minus the nonspecific deiodination (always $<1.5 \%$ ), obtained with the saturating concentration of T3 (200 nM). D3 activity expressed as fentomoles T3 per minute per milligram protein. All experiments were performed in triplicate in at least two independent experiments.

\section{Real-time PCR}

Total RNA was extracted from tissues with trizol method, cDNA was synthesized (SuperScript First-Strand Synthesis System for RT-PCR; Invitrogen), followed by a realtime PCR with SYBR Green PCR Master Mix (Applied Biosystems) in ABI Prism 7500 Sequence Detection System (Applied Biosystems) assay. The r2 was greater than 0.99, and the amplification efficiency varied between $80 \%$ and $100 \%$. Samples were measured by relative quantification (change in expression in the experimental group vs sham; untreated vs treated group). The primers used were: Dio3 (5'-TCCAGAGCCAGCACATCCT-3'; 5'-ACG TCGCGCTGGTACTTAGTG-3'), Ucp2 (5'-TCAACTGTACTG AGCTGGTGACCTA-3'; 5'-GGAGGTCGTCTGTCATGA GGTT-3'), Ucp3 (5'-ATGAGTTTTGCCTCCATTCG-3'; 5'-GGCGTATCATGGCTTGAAAT-3'), Klf9 (5'-AGTGCATAC AGGTGAACGGC-3'; 5'-AACGGAACTGCTTTTCCCCA-3') with the internal control cyclophilin A (F-5'-GTCAAC CCCACCGTGTTCTTC-3'; R-5'-ACTTGCCACCAGTGC CATTATG-3').

\section{Oxidative stress parameters}

\section{Carbonyl measurement}

Duplicate aliquots of $0.3 \mathrm{mg}$ of protein homogenate of each tissue were incubated with $500 \mu \mathrm{L}$ of $10 \mathrm{mM}$ 2.4-dinitrophenylhydrazine or $1.0 \mathrm{~mL}$ of $2 \mathrm{M} \mathrm{HCl}$ (blank tube). Two hundred fifty microliters of $50 \%$ trichloroacetic acid was added to the aliquots as previously described. The samples were subsequently centrifuged at $8000 \boldsymbol{g}$ for $30 \mathrm{~min}$ to obtain the protein pellets, immediately washed with ethanol-ethyl acetate at a 1:1 (v/v) ratio. The difference between the 2.4-dinitrophenylhydrazinetreated and $\mathrm{HCl}$-treated samples (blank) was used to calculate the carbonyl content determined at $370 \mathrm{~nm}$. Carbonyl content was calculated using the millimolar absorption coefficient of hydrazine (e370 $\mathrm{nm}=$ $21,000,000 \mathrm{M}^{-1} \mathrm{~cm}^{-1}$ ) and the results expressed in nmol carbonyl/mg protein.

\section{Sulfhydryl content}

Sulfhydryl content was measured according to the method of Aksenov \& Markesbery (2001), where the reduction of 5,5'-dithio-bis(2-nitrobenzoic acid) (DTNB) by thiols generates a yellow derivative (TNB) and measured at $412 \mathrm{~nm}$. In brief, $30 \mu \mathrm{L}$ of $0.1 \mathrm{mM}$ DTNB was added to $120 \mu \mathrm{L}$ of tissue supernatants. A 30-min incubation followed this at room temperature in darkness. Results were calculated as nmol of $\mathrm{TNB} / \mathrm{mg}$ of protein.

\section{Antioxidant defenses}

Reduced glutathione (GSH) levels were measured according to a standard method (Lehnen et al. 2017). Briefly, tissues were homogenized in the presence of $300 \mu \mathrm{L}$ of $20 \mathrm{mM}$ sodium phosphate and $140 \mathrm{mM} \mathrm{KCl}$ buffer, $\mathrm{pH} 7.4$, adding metaphosphoric sodium acid for a final ratio of $1: 1$ of precipitated protein. Samples were centrifuged and $15 \mu \mathrm{L}$ of tissue preparation incubated with an equal volume of ophthaldialdehyde ( $1 \mathrm{mg} / \mathrm{mL}$ methanol) at room temperature for $15 \mathrm{~min}$ in the presence of 20 volumes $(1: 20, \mathrm{v} / \mathrm{v})$ of $100 \mathrm{mM}$ sodium phosphate buffer, $\mathrm{pH}$ 8.0, containing 5 mM EDTA. Fluorescence was measured using wavelengths of $350 \mathrm{~nm}$ and $420 \mathrm{~nm}$. A calibration curve was generated using standard GSH $(0.001-0.1 \mathrm{mM})$, and GSH concentrations were calculated as $\mathrm{nmol} / \mathrm{mg}$ protein.

Oxidized glutathione (GSSG) levels were determined using the enzymatic recycling method as described (Teare et al. 1993). Briefly, tissues were homogenized in $4(\mathrm{w} / \mathrm{v})$ volumes of a sulfosalicylic acid solution (11\%) and Triton X-100 (0.11\%), (1:1 ratio). After incubating for $5 \mathrm{~min}$ at $4{ }^{\circ} \mathrm{C}$ with continuous shaking, the samples were centrifuged 
at $10,000 \boldsymbol{g}$ for $10 \mathrm{~min}\left(4^{\circ} \mathrm{C}\right)$, and the supernatant was collected for analyses of glutathione levels. For GSSG measurement, $10 \mu \mathrm{L}$ of the supernatant was added to $110 \mu \mathrm{L}$ of a GSH masking buffer (100 mM phosphate buffer, 1 mM EDTA, 1.1\% 2-vinylpyridine), $\mathrm{pH} 7.4$, and incubated for $1 \mathrm{~h}$ at room temperature. The samples prepared for GSSG measurement were subjected to enzymatic analysis in a recycling buffer system containing $300 \mu \mathrm{M}$ NADPH, $225 \mu \mathrm{M}$ DTNB, $1.6 \mathrm{U} / \mathrm{mL}$ GR, and $1.0 \mathrm{mM}$ EDTA in $100 \mathrm{mM}$ phosphate buffer ( $\mathrm{pH}$ 7.4). The linear increase in absorbance at $405 \mathrm{~nm}$ over time was monitored using a microplate reader (SpectraMax M5). Standard curves were generated using known amounts of GSH $(100 \mu \mathrm{M})$ and GSSG $(3.47,6.95,13.89 \mu \mathrm{M})$.

\section{Thioredoxin reductase, glutathione peroxide, and glutathione reductase activities}

Thioredoxin reductase activity ( $\mathrm{Tx}$ ) was measured using the Thioredoxin Reductase Assay Kit (Sigma-Aldrich) according to the manufacturer's instructions. Tissues from all groups were lysed with a buffer $(150 \mathrm{mmol} / \mathrm{L} \mathrm{NaCl}$, $50 \mathrm{mmol} / \mathrm{L}$ Tris- $\mathrm{HCl}, 1 \%$ Triton, $1 \%$ sodium dodecyl sulfate, $1 \%$ deoxycholate, $1 \mathrm{mmol} / \mathrm{L} \mathrm{NaF}$ and $1 \mathrm{mmol} / \mathrm{L}$ EDTA, and protease inhibitors). After centrifugation at 14,000 $\boldsymbol{g}$ for $10 \mathrm{~min}$ at $4{ }^{\circ} \mathrm{C}$, protein concentrations of supernatants were determined using the Bradford method. The sample was incubated in $100 \mathrm{mmol} / \mathrm{L}$ of potassium phosphate with $10 \mathrm{mmol} / \mathrm{L}$ EDTA and $0.24 \mathrm{mmol} / \mathrm{L} \mathrm{NADPH}$ with and without a Tx inhibitor of all isoforms. The reaction was started by adding 5,5'-dithiobis(2-nitrobenzoic) acid and monitored spectrophotometrically at $412 \mathrm{~nm}$. Enzymatic activity was quantified using the following equation: Unit $/ \mathrm{mL}=\mathrm{A} 412 \mathrm{~nm} / \mathrm{min}$ (thioredoxin reductase) $\times$ dil $\times$ volenz vol (dil $=$ sample dilution factor; vol $=$ volume of reaction in $\mathrm{mL}$; enzvol = volume of enzyme in $\mathrm{mL}$ ). Results were expressed as $\mathrm{nmol} / \mathrm{min} / \mathrm{mL}$.

Glutathione peroxidase (GPx) activity was determined using the Glutathione Peroxidase Assay Kit (SigmaAldrich) according to the manufacturer's instructions. Briefly, enzyme activity was determined in tissue crude homogenate by monitoring the NADPH disappearance at $340 \mathrm{~nm}$ and expressed as $\mathrm{nmol} / \mathrm{min} / \mathrm{mL}$.

Glutathione reductase (GR) activity was determined using the Glutathione Reductase Activity Assay Kit (Cayman Chemical) according to the manufacturer's instructions. Tissues were homogenized in cold $50 \mathrm{mM}$ potassium phosphate, $\mathrm{pH}$ 7.5, $1 \mathrm{mM}$ EDTA, and centrifuged at $10,000 \boldsymbol{g}$ for $15 \mathrm{~min}$ at $4{ }^{\circ} \mathrm{C}$, and protein concentrations of supernatants were determined using the Bradford method. The oxidation of NADPH identified the reduction of oxidized glutathione (GSSG) to GSH to $\mathrm{NADP}+$ at $340 \mathrm{~nm}$.

\section{Statistical analysis}

Unless otherwise specified, the results are presented as the mean \pm s.D. Data were analyzed using two-tailed Student's $t$-tests or one-way ANOVA followed by the post hoc Duncan multiple range tests when $\mathrm{F}$ was significant. Kruskal-Wallis test was performed when appropriate. The results from all animals are presented in the corresponding graphs. No outliners or any other results have been omitted within the analysis of data presented in this manuscript. Prism 8.0 software was used for statistical analyses and $P<0.05$ was considered significant.

\section{Results}

D3 is upregulated in the liver, muscle, and brain of rats subjected to myocardial infarction

Figure 1 shows that the levels of Dio3 mRNA were significantly increased in the MI-placebo group 10 days post-MI induction compared to that of the sham group: in liver ( five-fold, $P<0.001$, Fig. $1 \mathrm{~A})$, muscle ( eleven-fold, $P<0.001$, Fig. 1B), and brain ( three-fold, $P<0.001$, Fig. 1C). After 28 days, Dio3 mRNA levels were augmented in the liver and brain ( $\sim$ two-fold in both tissues, $P<0.01$, Fig. $1 \mathrm{~A}$ and $\mathrm{C}$ ) compared to that of the sham. NAC treatment attenuated the increases in the levels of Dio3 transcripts 10 days post-MI in the liver ( three-fold, $P<0.001$, Fig. $1 \mathrm{~A}$ ), muscle ( four-fold, $P<0.001$, Fig. 1B) and brain ( two-fold, $P<0.01$, Fig. 1C). D3 activity was markedly augmented 10 days post-MI in all tissues of the MI-placebo group compared to those levels in the sham group (liver 1 vs $5.7 \mathrm{fmol} / \mathrm{mg}$ prot $/ \mathrm{min}$; muscle $0.8 \mathrm{vs} 8 \mathrm{fmol} / \mathrm{mg}$ prot $/ \mathrm{min}$; brain 1.6 vs $5.2 \mathrm{fmol} / \mathrm{mg}$ prot $/ \mathrm{min}, P<0.001$, Fig. 1D, $\mathrm{E}$ and $\mathrm{F})$. Importantly, NAC treatment prevented the increases in D3 activity after MI induction in all studied tissues $(P>0.05$, Fig. $1 \mathrm{D}, \mathrm{E}$ and $\mathrm{F})$.

To evaluate whether the observed D3 augmented expression resulted in any putative modification of the tissue thyroid hormone status, we thought to analyze positively regulated thyroid hormone genes in each tissue: $U c p 2$ in liver, Klf9 in brain and $U c p 3$ in muscle. As expected, in the placebo group, we observed decreases in the Ucp2 mRNA levels more pronounced at day 10 $(P<0.0001)$ but still present at day $28(P=0.03$, Fig. $2 \mathrm{~A})$, suggesting decreases in the T3 tissue levels. A similar 

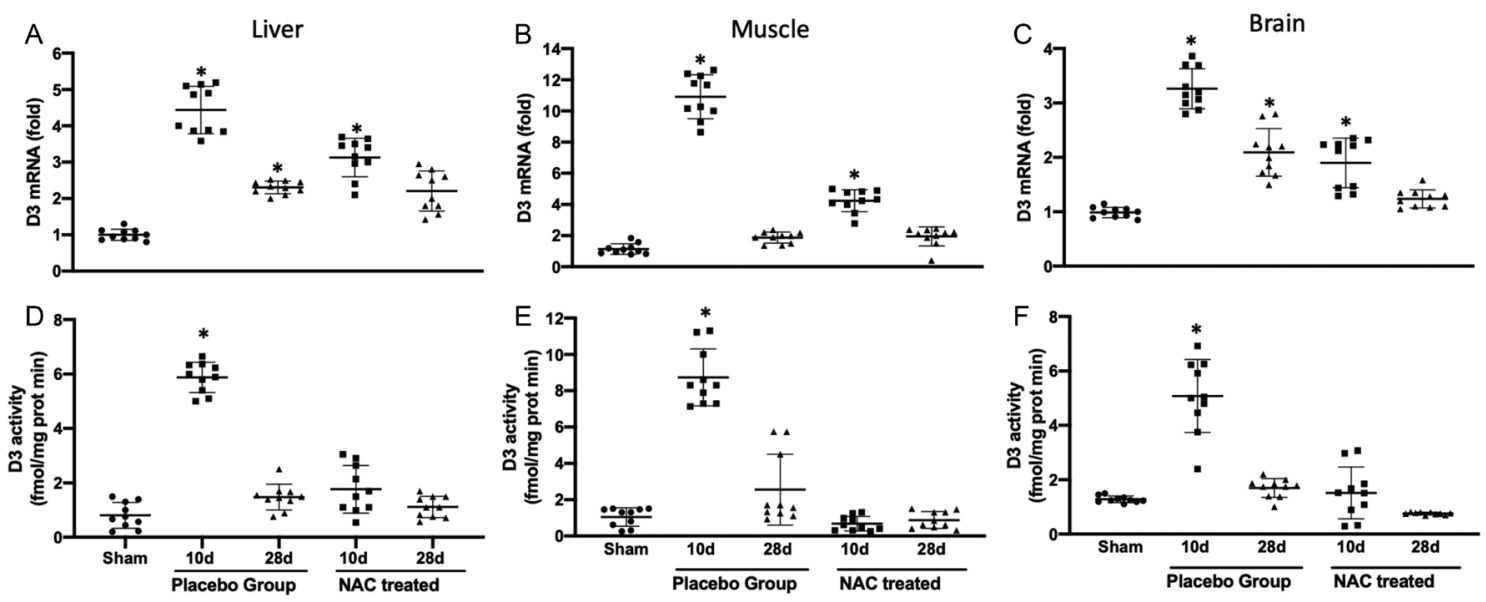

\section{Figure 1}

Levels of D3 mRNA and activity in the liver, muscle and brain. (A) D3 expression and activity were increased in the MI-placebo group 10 days post-MI induction in the liver. The same results were observed in (B) muscle and (C) brain. Twenty-eight days after MI induction, the level of D3 expression was increased in the MI-placebo group in the liver (A) and brain (C) but not in the muscle (B). NAC treatment prevented the increase in D3 expression 10 and 28 days post-MI induction in all tissues (A, B and C). ${ }^{*} P<0.001$, vs Sham, $n=10$ in each of the five groups. No outliers have been omitted within this analysis.

pattern was observed on the Klf9 gene in brain (10 and 28 days, $P<0.0001$ and $P=0.03$, respectively, Fig. 2B) and $U c p 3$ in muscle (at 10 days $P<0.0001$, Fig. 2C). These changes are fully corrected at day 28 , in the NACtreated groups.

\section{Deranged redox status: increased protein oxidation in the liver, muscle and brain}

Carbonyl content, a parameter of protein oxidation, was significantly increased 10 days post-MI induction in the MI-placebo group compared to that of the sham group in the liver $(0.12$ to $0.95 \mathrm{nmol} / \mathrm{mg}$ prot, $P<0.001$, Fig. $3 \mathrm{~A}$ ), muscle (0.08 to $2.9 \mathrm{nmol} / \mathrm{mg}$ prot, $P<0.001$, Fig. 3B) and brain (0.03 to $0.89 \mathrm{nmol} / \mathrm{mg}$ prot, $P<0.001$, Fig. 3C). At 28 days post-MI induction, the carbonyl content was increased in the liver $(0.12$ to $0.89 \mathrm{nmol} / \mathrm{mg}$ prot, $P<0.001$, Fig. 3A) and brain $(0.03$ to $0.46 \mathrm{nmol} / \mathrm{mg}$ prot $P<0.001$, Fig. 3C) but not in the muscle $(0.08$ to $0.13 \mathrm{nmol} / \mathrm{mg}$ prot, $P>0.05$, Fig. $3 \mathrm{~B}$ ) in the MI-placebo group compared to the content in these organs in the sham group. NAC treatment prevented the increase in carbonyl content in all tissues 10 and 28 days post-MI induction (Fig. 3A, B and C).

We then determined the sulfhydryl content, which is inversely correlated with oxidative damage to proteins and reflects GSH levels as well as other thiol group-containing compounds. Decreased sulfhydryl was observed in the liver (62 to $50 \mathrm{nmolTNB} / \mathrm{mg}$ prot, $P<0.001$, Fig. $4 \mathrm{~A}$ ), muscle (25 to $17 \mathrm{nmolTNB} / \mathrm{mg}$ prot, $P<0.001$, Fig. $4 \mathrm{~B}$ ), and brain (22 to $15 \mathrm{nmolTNB} / \mathrm{mg}$ prot, $P<0.001$, Fig. $4 \mathrm{C}$ ) 10 days, but not 28 days, after MI induction in the placebo group (Fig. 4). NAC treatment prevented the decreased in sulfhydryl content in all tissues.
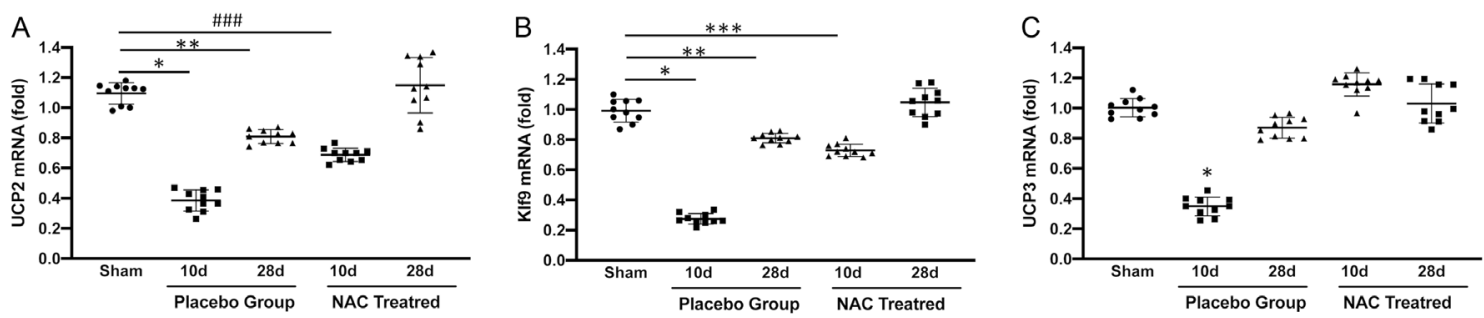

\section{Figure 2}

Levels of Ucp2, KIf9 and Ucp3 mRNA in the liver, brain and muscle. (A) Ucp2 expression was decreased in liver in the MI-placebo group 10 days $\left({ }^{*} P<0.0001\right)$ and 28 days ( $\left.{ }^{*} P=0.03\right)$ and 10 days post-MI induction in the NAC treated (\#\#\#P=0.009). (B) Similar results were observed with the KIf9 expression in brain $(* P<0.0001, * \star P=0.03, * \star * P=0.01)$. Twenty-eight days after MI induction, the level of $U c p 2$ or $K l f 9$ expression were not different from Sham in the NAC treated groups. Expression of Ucp3 (C) in the muscle was decreased only after 10 days in MI-placebo group but not in the other groups. ${ }^{*} P<0.0001$ vs Sham, $n=10$ in each of the five groups. No outliers have been omitted within this analysis. 

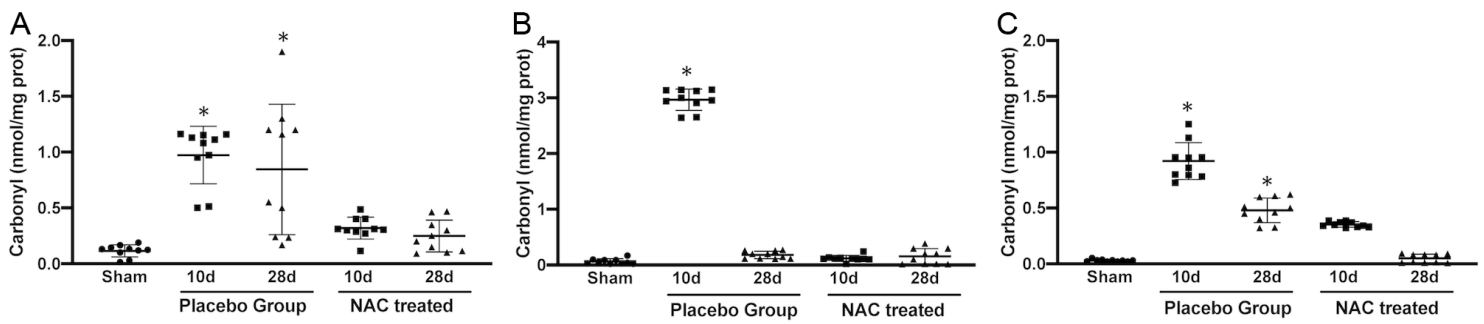

\section{Figure 3}

Carbonyl group levels in the liver, muscle and brain. The carbonyl content was increased in the placebo group 10 days after MI induction in the liver (A), muscle (B) and brain (C). Twenty-eight days post-MI induction, the carbonyl content was increased only in liver (A) and in the brain (C) in the placebo group. In the NAC group, the carbonyl content was decreased after 10 and 28 days (A, B and C). All data, $* P<0.001$ vs Sham, $n=10$ in each of the five groups. No outliers have been omitted within this analysis.

\section{Decreased levels of reduced glutathione (GSH) and increased levels of oxidized glutathione (GSSG) in the liver, muscle and brain}

Next, the concentrations of the nonenzymatic antioxidant GSH were determined in all tissues. GSH content was diminished in liver (31.2 to $26.3 \mathrm{nmol} / \mathrm{mg}$ prot, $P<0.001$, Fig. $5 \mathrm{~A}$ ), muscle (30.8 to $23.4 \mathrm{nmol} / \mathrm{mg}$ prot, $P<0.001$, Fig. $5 \mathrm{~B})$ and brain $(29.8$ to $26 \mathrm{nmol} / \mathrm{mg}$ prot, $P<0.001$, Fig. 5 C) tissues in the MI-placebo animals 10 days, but not 28 days, after MI induction. Again, NAC treatment prevented the decrease in GSH concentrations in all the tissues evaluated. On the other hand, GSSG concentrations were increased in parallel to the decreased GSH in liver ( 0.8 to $2.7 \mathrm{nmol} / \mathrm{mg}$ prot, $P<0.001$, Fig. $5 \mathrm{~A}, \mathrm{~B}$ ), muscle (0.9 vs $2.9 \mathrm{nmol} / \mathrm{mg}$ prot, $P<0.001$, Fig. $5 \mathrm{~B}, \mathrm{~B}$ ) and brain (1.1 to $2.3 \mathrm{nmol} / \mathrm{mg}$ prot, $P<0.001$, Fig. 5C, B) tissue of MI-placebo animals at 10 days, but not at 28 days, after MI. Again, NAC treatment significantly attenuated the increase in GSSG levels in liver and muscle and completely prevented the elevation of GSSG concentration in the brain.

Interestingly, D3 activity correlates with thiol concentration parameters. GSH and sulfhydryl levels were inversely correlated with D3 activity in the liver $(P<0.0001$, Fig. 6A), muscle $(P<0.0001$, Fig. 6B) and brain $(P<0.0001$, Fig. 6C).

\section{Antioxidant enzymatic defenses in the liver, muscle and brain}

We then determined the antioxidant enzyme activities of GPx, GR and Tx in all groups of animals in the liver, muscle and brain. As shown in Fig. 7, in the MI-placebo group, the GPx activity was augmented 10 days after MI induction in the liver and muscle (40 to $136 \mathrm{U} / \mathrm{mg}$ prot and 8 to $32 \mathrm{U} / \mathrm{mg}$ prot, respectively, $P<0.001$, Fig. $7 \mathrm{~A}$ and $\mathrm{B})$ but not in the brain (31 to $28 \mathrm{U} / \mathrm{mg}$ prot, $P>0.05$, Fig. 7 C). Furthermore, the level of GPx activity in the placebo group was similar to that of the sham group 28 days post-MI induction in the liver (40 to $39 \mathrm{U} / \mathrm{mg}$ prot, $P>0.05$, Fig. $7 \mathrm{~A}$ ) and brain (31 to $28 \mathrm{U} / \mathrm{mg}$ prot, $P>0.05$, Fig. $7 \mathrm{C}$ ) but remained augmented in the muscle ( 8 to $12 \mathrm{U} / \mathrm{mg}$ prot, $P<0.001$, Fig. $7 \mathrm{~B}$ ). NAC treatment completely prevented this increase in the liver and muscle. GR activity was significantly elevated only in the liver 10 days post-MI induction in the MI-placebo group (6 to $21 \mathrm{nmol} / \mathrm{min} / \mathrm{mL}, \mathrm{P} \leq 0.0001$ ), whereas NAC treatment attenuated this increase $(21$ to $15 \mathrm{nmol} / \mathrm{min} / \mathrm{mL}$,
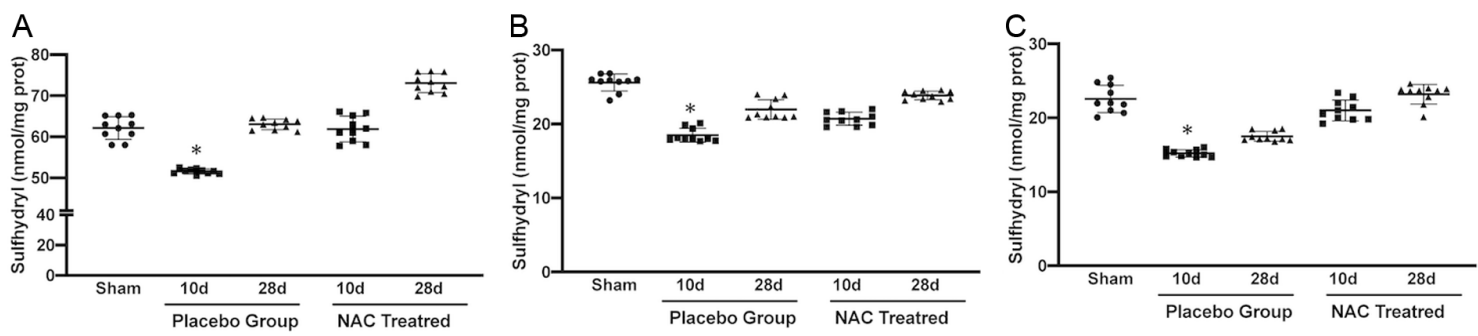

\section{Figure 4}

Sulfhydryl group levels in the liver, muscle and brain. The sulfhydryl content was decreased in the placebo group 10 days post-MI induction in the liver (A), muscle (B) and brain (C). Twenty-eight days post-MI induction, no difference was observed between the groups. $* P<0.001$ vs Sham. $n=10$ in each of the five groups. No outliers have been omitted within this analysis. 

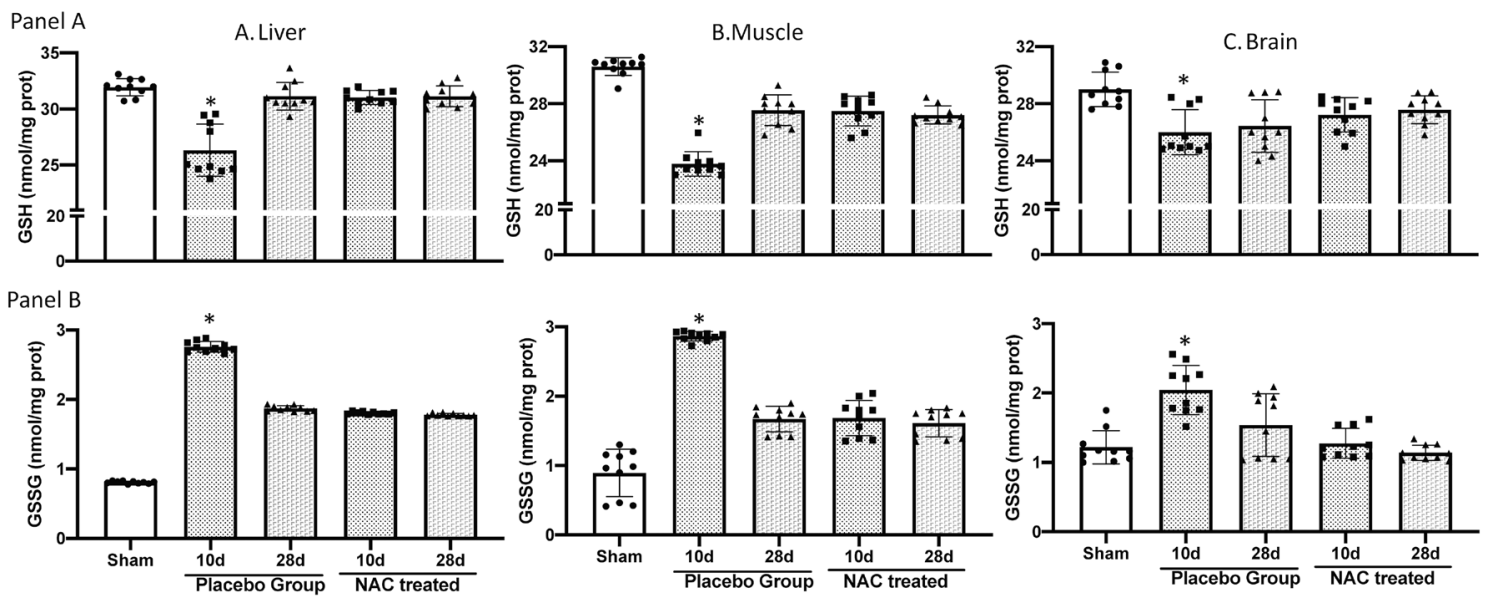

\section{Figure 5}

(Top) Changes in GSH levels in the liver (A), muscle (B) and brain (C). GSH content was diminished in the liver, muscle and brain tissue sample from the MI-placebo animals, but not in the MI-NAC treated animals, 10 days after MI induction. Twenty-eight days post-MI induction, the GSH content had returned to the initial level. (Bottom) Changes in GSSG levels in the liver (A), muscle (B) and brain (C). GSSG content was increased in the liver, muscle and brain tissue of the MI-placebo animals, and this increase was significantly attenuated in the liver and muscle and completely prevented in brain tissues of the MI-NAC treated animals 10 days post-MI induction. Twenty-eight days post-MI induction, we observed that the GSSG content had returned to the initial level. ${ }^{*} P<0.001$, vs MI-placebo group, $n=10$ in each group (Placebo or NAC-Treated). No outliers have been omitted within this analysis.

$P=0.03$, respectively, Fig. 7D). No difference in GR activity was observed after 28 days in any of the groups.

Finally, thioredoxin reductase (Tx) activity was augmented 10 days post-IM induction in the liver and muscle $(0.18$ to $0.24 \mathrm{U} / \mathrm{mg}$ prot, $P<0.01$ and 0.16 to $0.3, P=0.004$, respectively, Fig. $7 \mathrm{G}$ and $\mathrm{H})$. No difference was observed in the brain tissue $(0.29$ to $0.32 \mathrm{U} / \mathrm{mg}$ prot $P>0.05$, Fig. 7I) at this time post-MI induction. NAC treatment restored $\mathrm{Tx}$ activity to the level of the sham group in the liver 10 days after MI induction (0.18 to 0.24 $\mathrm{U} / \mathrm{mg}$ prot, $P<0.01$, Fig. $7 \mathrm{G})$.

\section{Discussion}

The present study aimed to investigate the interrelationship of D3 function and redox homeostasis in brain, liver and skeletal muscle in a model of NTIS. The results showed
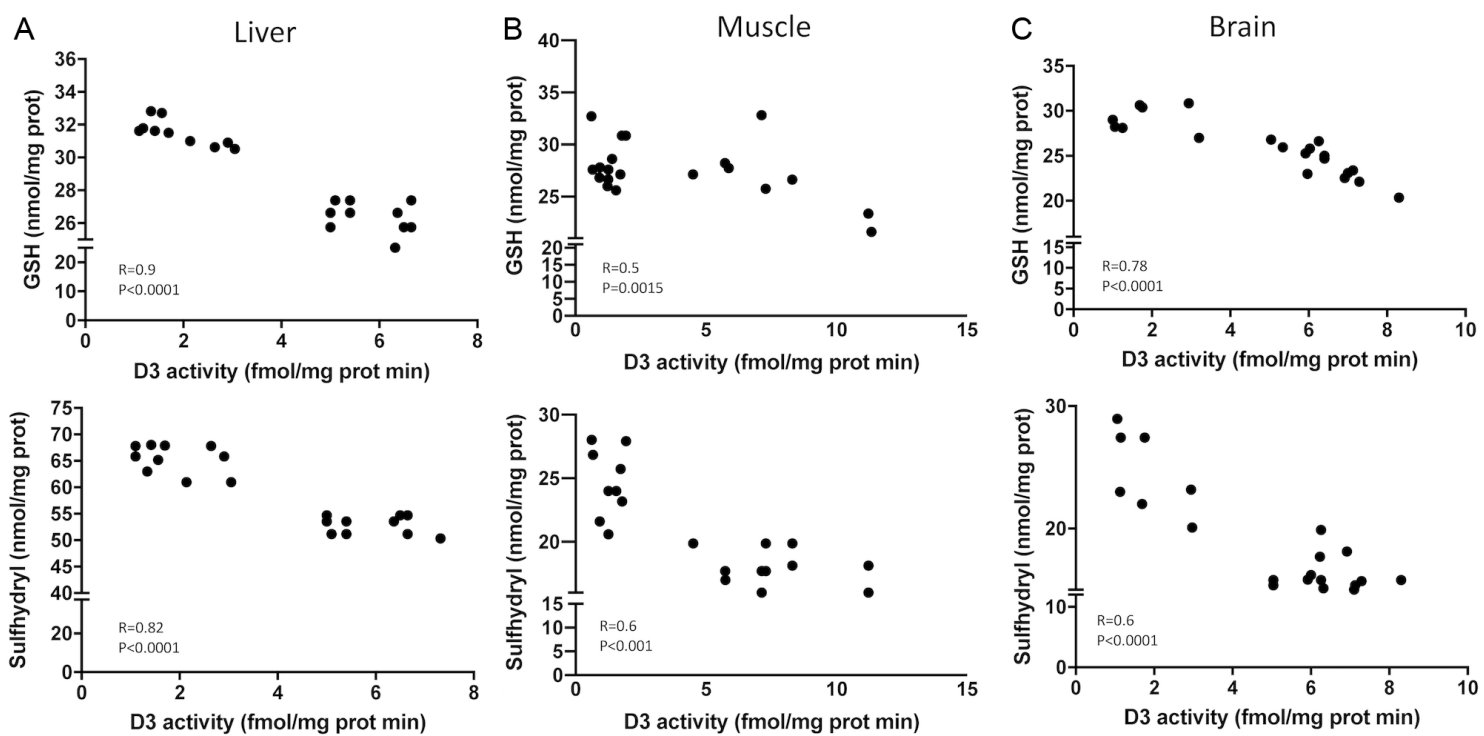

Figure 6

The GSH and sulfhydryl levels are inversely correlated with D3 activity in the liver $(P<0.0001, \mathrm{~A})$, muscle $(P<0.0001, \mathrm{~B})$ and brain $(P<0.0001, \mathrm{C}) . n=10$ in each group (10 or 28 days). No outliers have been omitted within this analysis. 


\begin{tabular}{l|l|l|l|l|}
$\begin{array}{l}\text { Journal of } \\
\text { Endocrinology }\end{array}$ & T Ederich Lehnen et al. & $\begin{array}{l}\text { Remote induction of D3 by } \\
\text { stress in disease }\end{array}$ & $\mathbf{2 4 6 : 3}$ & $\mathbf{2 4 4}$ \\
\hline
\end{tabular}
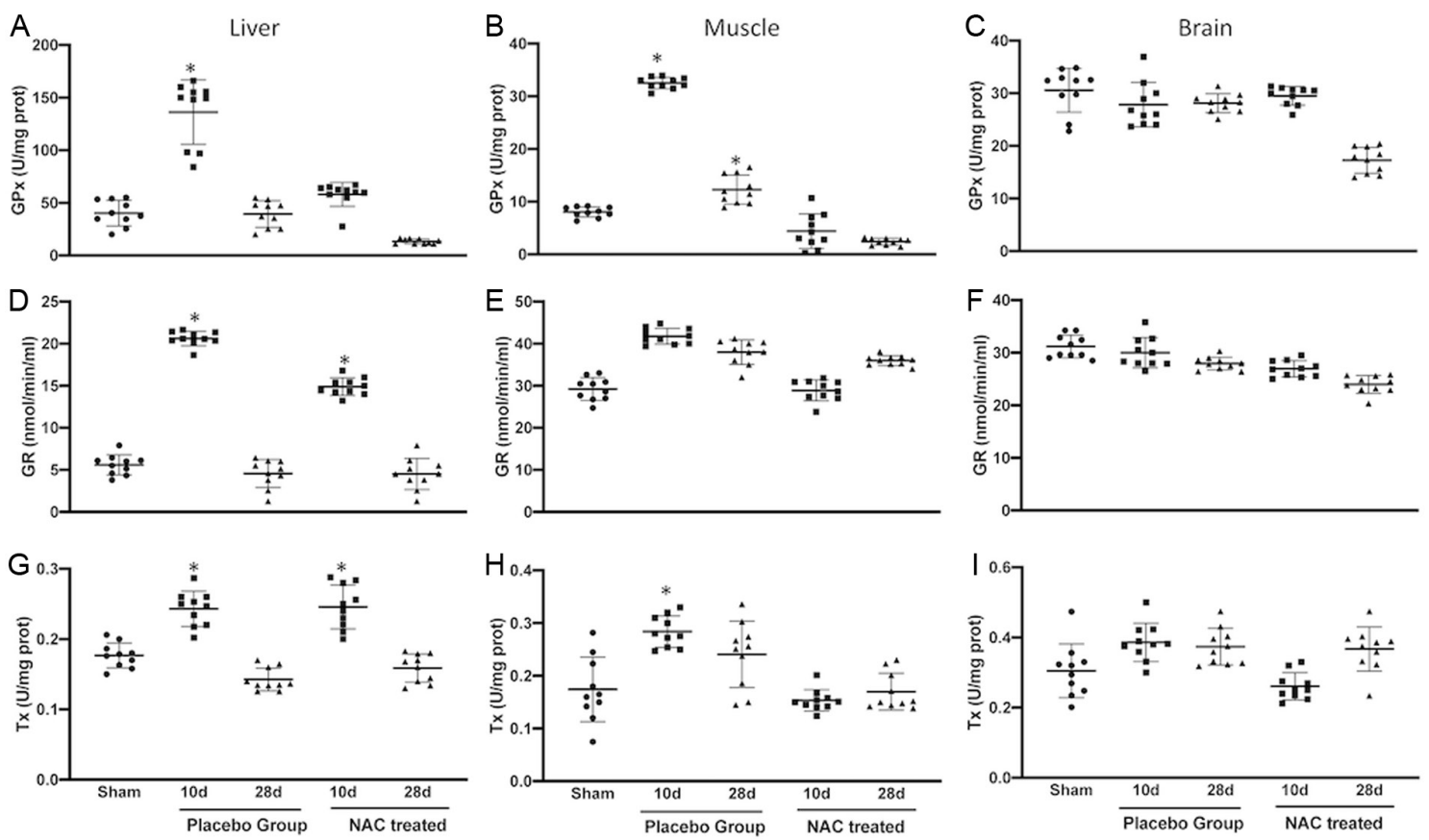

Figure 7

Glutathione peroxidase (GPx), glutathione reductase (GR) and thioredoxin reductase (Tx). GPx is augmented in the liver and muscle 10 days post-MI induction, but not in the brain. Glutathione reductase levels are augmented only in the liver, while Tx levels are augmented in liver and muscle 10 days post-MI induction. No outliers have been omitted within this analysis.

that altered GSH and sulfhydryl levels in all studied tissues paralleled in increase in induced D3 function. Moreover, the GPx, GR and Tx enzymes were also altered in the scenario of disease. Importantly, NAC treatment prevented D3 alterations and ameliorated the redox alterations previously observed. These results support the view that decreased T3 levels observed in disease states might be secondary to generalized and tissue-specific augmented thyroid hormone inactivation by D3 induction.

Increased D3 expression was previously demonstrated in the liver, muscle and adipose tissue of deceased patients who had septic shock (Peeters et al. 2003, 2005, Rodriguez-Perez et al. 2008). It was also shown in mice with a specific hepatocyte deficiency of D3 after liver injury, and regardless of the absence of D3 in the liver, NTIS was observed (Castroneves et al. 2014). The altered D3 function observed in the liver, muscle and brain described here reinforces the hypothesis that the D3 response might be generalizable to other types of illness, which helps explain why distinct diseases have the same pattern of thyroid hormone alterations. Interestingly, even after 4 weeks of injury, animals presented with altered D3 expression in their livers and brains. These sustained alterations in D3 activity have, thus far, been described only in heart tissue after MI (Olivares et al. 2007, Pol et al. 2011, Lehnen et al. 2017). Of interest, the observed increases in D3 activity correlate with downregulation of genes positively regulated by thyroid hormones (Ramadan et al. 2011, Dugas et al. 2012, Sinha et al. 2018), (Fig. 2). These findings might reflect lower levels of T3 availability in tissues, unraveling additional adverse tissue-related effects.

We have previously shown that D3 is induced by pro-oxidant alterations in disease states (Vidart et al. 2014, Wajner et al. 2011, Lehnen et al. 2017). However, only the organ that was primarily affected was studied, not the systemic role of D3 in a one-organ disease such as MI. Considering the observed alterations in protein oxidation, sulfhydryl content and GSH/GSSG levels, some hypotheses that could potentially explain the dynamics between D3 and redox alterations in disease states can be addressed. For example, the parallel observed between augmented D3 expression levels and the oxidation of protein-bound sulfhydryl groups could have led to altered function. Cell homeostasis requires several cytosolic reactions, including those that maintain the reduced thiol state of the cysteine protein residues (MoriartyCraige \& Jones 2004, Oliveira \& Laurindo 2018). Although the effect of NAC on D3 function is not yet completely understood, NAC must be considered a major cysteine donator, which not only generates GSH but also reduces various thiol- containing enzymes, such as D3 
(Lamirand et al. 2008, Wajner et al. 2011, Wajner et al. 2015). The observed D3 alterations also correlated with variations in GSH and GSSG content of the examined tissues, which maintain D3 function in a normal state at a level similar to that observed in sham animals or untreated cells (Wajner et al. 2011, Lehnen et al. 2017). NAC could also provide the cysteine/sulfhydryl content necessary for GSH, consequently affecting D3 function and/or localization in cell tissues. The formation of redox-active disulfide bonds that generate reversible combinations of a cysteine residue and a small-molecule thiol resulting in glutathionylated adducts could be another option (Couvertier et al. 2014, Mailloux \& Willmore 2014). Moreover, it is known that under disease DIO3 transcription is augmented by different mechanisms (Lamirand et al. 2008, Wajner et al. 2011). Interestingly, low levels of GSH, in a cell culture of astrocytes, augmented D3 mRNA stability (Lamirand et al. 2008). This possibility could be considered in NTIS.

Alterations in the regeneration of the D3 enzyme must also be considered,since it is known that D3 is regenerated from early endosomes and that this mechanism could be altered in diseases through diminished levels of circulating GSH, which modifies the dynamics of the plasma membrane components (Baqui et al. 2003). One, or most likely a combination, of these mechanisms could also help to explain the differences observed between D3 expression and D3 activity observed over time and their dependence on the redox status in each tissue.

Deiodinases can be reduced by Tx and GPx (Goswami \& Rosenberg 1985, Sawada et al. 1986). Tx reduces proteins with disulfide bonds by transferring electrons from reactive cysteines to maintain most intracellular proteins in a reduced state (Schweizer et al. 2014, Rhee 2016, Oliveira \& Laurindo 2018). Moreover, in the Tx-fold family, both glutathione peroxidase (GPx) and glutathione reductase (GR) interact with GSH and GSSG to exchange thiols, thus reversing the redox alterations in the organism (Callebaut et al. 2003, Deponte 2013). The oxidoreductase GR reduces GSSG into two molecules of GSH, through access to the thiol/disulfide-pool, which maintain appropriate redox conditions (Deponte 2013). Interestingly, overexpression of $\mathrm{Tx}$ reduces disulfide oxidoreductase activity in the heart by decreasing the oxidative stress under pathological conditions (Yamamoto et al. 2003). Although several questions have yet to be answered, one can observe that the correlation between deiodinase function and the glutathione family relies mostly on variations in the amounts of GSH and thiols (sulfhydryl levels) present in each tissue, likely through the reversal and/or reorganization of one of the mechanisms described previously.

Taken together, our findings demonstrate that oxidative stress occurs in multiple tissues after MI induction and results in the systemic induction of D3. The amelioration of MI-related redox imbalance by NAC prevents changes in thyroid hormone metabolism by preventing the increase in D3 expression and activity systemically. The results shown here suggest that D3 might orchestrate NTIS. The normal circulating thyroid hormone levels are, therefore, dependent on the maintenance of a reduced cellular redox environment throughout the whole body.

\section{Declaration of interest}

The authors declare that there is no conflict of interest that could be perceived as prejudicing the impartiality of the research reported.

\section{Funding}

This work was supported by Conselho Nacional de Desenvolvimento Científico e Tecnológico (CNPq, numbers 403373, 301585) and Fundo de Incentivo a Pesquisa do Hospital de Clínicas de Porto Alegre (FIPE), Brazil.

\section{References}

Aksenov MY \& Markesbery WR 2001 Changes in thiol content and expression of glutathione redox system genes in the hippocampus and cerebellum in Alzheimer's disease. Neuroscience Letters 302 141-145. (https://doi.org/10.1016/s0304-3940(01)01636-6)

Alevizaki M, Synetou M, Xynos K, Pappa T \& Vemmos KN 2007 Low triiodothyronine: a strong predictor of outcome in acute stroke patients. European Journal of Clinical Investigation 37 651-657. (https:// doi.org/10.1111/j.1365-2362.2007.01839.x)

Baqui M, Botero D, Gereben B, Curcio C, Harney JW, Salvatore D, Sorimachi K, Larsen PR \& Bianco AC 2003 Human type 3 iodothyronine selenodeiodinase is located in the plasma membrane and undergoes rapid internalization to endosomes. Journal of Biological Chemistry 278 1206-1211. (https://doi.org/10.1074/jbc.M210266200)

Bechtel TJ \& Weerapana E 2017 From structure to redox: the diverse functional roles of disulfides and implications in disease. Proteomics 17 1-27. (https://doi.org/10.1002/pmic.201600391)

Callebaut I, Curcio-Morelli C, Mornon JP, Gereben B, Buettner C, Huang S, Castro B, Fonseca TL, Harney JW, Larsen PR, et al. 2003 The iodothyronine selenodeiodinases are thioredoxin-fold family proteins containing a glycoside hydrolase clan GH-A-like structure. Journal of Biological Chemistry 278 36887-36896. (https://doi.org/10.1074/jbc. M305725200)

Castroneves LA, Jugo RH, Maynard MA, Lee JS, Wassner AJ, Dorfman D, Bronson RT, Ukomadu C, Agoston AT, Ding L, et al. 2014 Mice with hepatocyte-specific deficiency of type 3 deiodinase have intact liver regeneration and accelerated recovery from nonthyroidal illness after toxin-induced hepatonecrosis. Endocrinology 155 4061-4068. (https:// doi.org/10.1210/en.2013-2028)

Couvertier SM, Zhou Y \& Weerapana E 2014 Chemical-proteomic strategies to investigate cysteine posttranslational modifications. 
Biochimica \& Biophysica Acta 1844 2315-2330. (https://doi. org/10.1016/j.bbapap.2014.09.024)

Deponte M 2013 Glutathione catalysis and the reaction mechanisms of glutathione-dependent enzymes. Biochimica \& Biophysica Acta 1830 3217-3266. (https://doi.org/10.1016/j.bbagen.2012.09.018)

Dugas JC, Ibrahim A \& Barres BA 2012 The T3-induced gene KLF9 regulates oligodendrocyte differentiation and myelin regeneration. Molecular \& Cellular Neurosciences 50 45-57. (https://doi.org/10.1016/j. mcn.2012.03.007)

Goswami A \& Rosenberg IN 1985 Purification and characterization of a cytosolic protein enhancing GSH-dependent microsomal iodothyronine 5'-monodeiodination. Journal of Biological Chemistry $2606012-6019$.

Huang SA, Mulcahey MA, Crescenzi A, Chung M, Kim BW, Barnes C, Kuijt W, Turano H, Harney J \& Larsen PR 2005 Transforming growth factor-beta promotes inactivation of extracellular thyroid hormones via transcriptional stimulation of type 3 iodothyronine deiodinase. Molecular Endocrinology 19 3126-3136. (https://doi.org/10.1210/me.2005-0173)

Iervasi G, Pingitore A, Landi P, Raciti M, Ripoli A, Scarlattini M, L'abbate A \& Donato L 2003 Low-T3 syndrome: a strong prognostic predictor of death in patients with heart disease. Circulation 107 708-713. (https://doi.org/10.1161/01.cir.0000048124.64204.3f)

Kilkenny C, Browne WJ, Cuthill IC, Emerson M \& Altman DG 2010 Improving bioscience research reporting: the ARRIVE guidelines for reporting animal research. Journal of Pharmacology \& Pharmacotherapeutics 1 94-99. (https://doi.org/10.4103/0976-500X.72351)

Kuiper GG, Klootwijk W \& Visser TJ 2002 Substitution of cysteine for a conserved alanine residue in the catalytic center of type II iodothyronine deiodinase alters interaction with reducing cofactor. Endocrinology 143 1190-1198. (https://doi.org/10.1210/endo.143.4.8738)

Lamirand A, Pallud-Mothre S, Ramauge M, Pierre M \& Courtin F 2008 Oxidative stress regulates type 3 deiodinase and type 2 deiodinase in cultured rat astrocytes. Endocrinology 149 3713-3721. (https://doi. org/10.1210/en.2007-1462)

Lehnen TE, Santos MV, Lima A, Maia AL \& Wajner SM 2017 $\mathrm{N}$-acetylcysteine prevents low T3 syndrome and attenuates cardiac dysfunction in a male rat model of myocardial infarction. Endocrinology 158 1502-1510. (https://doi.org/10.1210/en.2016-1586)

Lu J \& Holmgren A 2009 Selenoproteins. Journal of Biological Chemistry 284 723-727. (https://doi.org/10.1074/jbc.R800045200)

Mailloux RJ \& Willmore WG 2014 S-glutathionylation reactions in mitochondrial function and disease. Frontiers in Cell \& Developmental Biology 2 68. (https://doi.org/10.3389/fcell.2014.00068)

Moriarty-Craige SE \& Jones DP 2004 Extracellular thiols and thiol/ disulfide redox in metabolism. Annual Review of Nutrition 24 481-509. (https://doi.org/10.1146/annurev.nutr.24.012003.132208)

NIH 1996 Guide for the Care and Use of Laboratory Animals. Washingtion, DC, USA: National Academy Press.

Olivares EL, Marassi MP, Fortunato RS, Da Silva AC, Costa-E-Sousa RH, Araujo IG, Mattos EC, Masuda MO, Mulcahey MA, Huang SA, et al. 2007 Thyroid function disturbance and type 3 iodothyronine deiodinase induction after myocardial infarction in rats a time course study. Endocrinology 148 4786-4792. (https://doi.org/10.1210/en.2007-0043)

Oliveira PVS \& Laurindo FRM 2018 Implications of plasma thiol redox in disease. Clinical Science 132 1257-1280. (https://doi.org/10.1042/ CS20180157)

Peeters RP, Wouters PJ, Kaptein E, Van Toor H, Visser TJ \& Van Den Berghe G 2003 Reduced activation and increased inactivation of thyroid hormone in tissues of critically ill patients. Journal of Clinical Endocrinology \& Metabolism 88 3202-3211. (https://doi.org/10.1210/jc.2002-022013)

Peeters RP, Wouters PJ, Van Toor H, Kaptein E, Visser TJ \& Van Den Berghe G 2005 Serum 3,3',5'-triiodothyronine (rT3) and
3,5,3'-triiodothyronine/rT3 are prognostic markers in critically ill patients and are associated with postmortem tissue deiodinase activities. Journal of Clinical Endocrinology \& Metabolism 90 4559-4565. (https://doi.org/10.1210/jc.2005-0535)

Pfeffer MA, Pfeffer JM, Fishbein MC, Fletcher PJ, Spadaro J, Kloner RA \& Braunwald E 1979 Myocardial infarct size and ventricular function in rats. Circulation Research 44 503-512. (https://doi.org/10.1161/01. res.44.4.503)

Pol CJ, Muller A, Zuidwijk MJ, Van Deel ED, Kaptein E, Saba A, Marchini M, Zucchi R, Visser TJ, Paulus WJ, et al. 2011 Leftventricular remodeling after myocardial infarction is associated with a cardiomyocyte-specific hypothyroid condition. Endocrinology 152 669-679. (https://doi.org/10.1210/en.2010-0431)

Ramadan W, Marsili A, Larsen PR, Zavacki AM \& Silva JE 2011 Type-2 iodothyronine deiodinase in skeletal muscle of C57BL/6 mice. II. Evidence for a role of D2 in the hypermetabolism of thyroid hormone receptor alpha-deficient mice. Endocrinology 152 3093-3102. (https:// doi.org/10.1210/en.2011-0139)

Rhee SG 2016 Overview on peroxiredoxin. Molecules \& Cells 39 1-5. (https://doi.org/10.14348/molcells.2016.2368)

Rodriguez-Perez A, Palos-Paz F, Kaptein E, Visser TJ, Dominguez-Gerpe L, Alvarez-Escudero J \& Lado-Abeal J 2008 Identification of molecular mechanisms related to nonthyroidal illness syndrome in skeletal muscle and adipose tissue from patients with septic shock. Clinical Endocrinology 68 821-827. (https://doi.org/10.1111/j.1365-2265.2007.03102.x)

Sawada K, Hummel BC \& Walfish PG 1986 Properties of cytosolic components activating rat hepatic 5 '-deiodination in the presence of NADPH. Biochemical Journal 234 391-398. (https://doi.org/10.1042/ bj2340391)

Schweizer U, Schlicker C, Braun D, Kohrle J \& Steegborn C 2014 Crystal structure of mammalian selenocysteine-dependent iodothyronine deiodinase suggests a peroxiredoxin-like catalytic mechanism. PNAS 111 10526-10531. (https://doi.org/10.1073/pnas.1323873111)

Sinha RA, Singh BK \& Yen PM 2018 Direct effects of thyroid hormones on hepatic lipid metabolism. Nature Reviews. Endocrinology 14 259-269. (https://doi.org/10.1038/nrendo.2018.10)

Teare JP, Punchard NA, Powell JJ, Lumb PJ, Mitchell WD \& Thompson RP 1993 Automated spectrophotometric method for determining oxidized and reduced glutathione in liver. Clinical Chemistry 39 686-689. (https://doi.org/10.1093/clinchem/39.4.686)

Vidart J, Wajner SM, Leite RS, Manica A, Schaan BD, Larsen PR \& Maia AL $2014 \mathrm{~N}$-acetylcysteine administration prevents nonthyroidal illness syndrome in patients with acute myocardial infarction: a randomized clinical trial. Journal of Clinical Endocrinology \& Metabolism 99 4537-4545. (https://doi.org/10.1210/jc.2014-2192)

Wajner SM, Goemann IM, Bueno AL, Larsen PR \& Maia AL 2011 IL-6 promotes nonthyroidal illness syndrome by blocking thyroxine activation while promoting thyroid hormone inactivation in human cells. Journal of Clinical Investigation 121 1834-1845. (https://doi. org/10.1172/JCI44678)

Wajner SM \& Maia AL 2012 New insights toward the acute nonthyroidal illness syndrome. Frontiers in Endocrinology 3 8. (https://doi. org/10.3389/fendo.2012.00008)

Wajner SM, Rohenkohl HC, Serrano T \& Maia AL 2015 Sodium selenite supplementation does not fully restore oxidative stress-induced deiodinase dysfunction: implications for the nonthyroidal illness syndrome. Redox Biology 6 436-445. (https://doi.org/10.1016/j. redox.2015.09.002)

Yamamoto M, Yang G, Hong C, Liu J, Holle E, Yu X, Wagner T, Vatner SF \& Sadoshima J 2003 Inhibition of endogenous thioredoxin in the heart increases oxidative stress and cardiac hypertrophy. Journal of Clinical Investigation 112 1395-1406. (https://doi.org/10.1172/JCI17700)

Received in final form 11 June 2020

Accepted 25 June 2020

Accepted Manuscript published online 25 June 2020 https://joe.bioscientifica.com https://doi.org/10.1530/JOE-19-0574 (c) 2020 Society for Endocrinology Published by Bioscientifica Ltd. Printed in Great Britain 